\title{
The Relationship of Organizational Commitment and Political Behavior Tendency among the Employees of Tehran University of Medical Sciences
}

\author{
Raadabadi Mehdi ${ }^{1}$, Mojbafan Arezoo ${ }^{2}$, Rajabi Vasokolaee Ghasem ${ }^{2} \&$ Dargahi Hossein $^{3}$ \\ ${ }^{1}$ Health Services Management Research Center, Institute for Futures Studies in Health, Kerman University of \\ Medical Sciences, Kerman, Iran \\ ${ }^{2}$ Department of Health Care Management, School of Allied Medicine, Tehran University of Medical Sciences, \\ Tehran, Iran \\ ${ }^{3}$ Department of Health Care Management, School of Allied Medicine, Research Center for Health Information \\ Management, Tehran University of Medical Sciences, Tehran, Iran
}

Correspondence: Dargahi Hossein, Professor in Health Care Management, School of Allied Medicine, University of Medical Sciences, Health Information Management Research Center, Enghelab AVE, Ghods ST, No 17, Tehran, Iran. Tel: 98-21-8898-2997. E-mail: hdargahi@sina.tums.ac.ir

Received: February 18, $2015 \quad$ Accepted: March 16, $2015 \quad$ Online Published: July 6, 2015
doi:10.5539/ass.v11n21p62
URL: http://dx.doi.org/10.5539/ass.v11n21p62

\begin{abstract}
Emphasis on organizational commitment of employees and its relation with organizational commitment which due to decease organizational performance, efficiency, and productivity is a huge influx of researchers. This study aimed to determine and measure the relationship between employees' organizational commitment and their tendency to display organizational behavior. This study was a descriptive-analytical and cross-sectional research that was conducted on the employees of Tehran University of Medical Sciences during 2013-2014. The sample size was calculated by Cochran formula as 150 employees in each of the areas. Two researcher made questionnaires were used as the research tools of political behavior, and the other one was Allen \& Meyer's organizational commitment. The validity and reliability of two questionnaires were confirmed. The response rate was $85 \%$. The collected data was inserted in Excel software. For preparing descriptive tables and results, SPSS 19 was used and for the analysis of data, $\mathrm{K}^{2}$ Test, one sample T-test, and Pearson test were used. The average of employees' organizational commitment was 62.32 which indicated that it was at a moderate level. In addition, the majority of the employees did not have the tendency to show political behavior. There was a significant relationship between employees' organizational commitment and their organizational position or tenure $(\mathrm{P}=0.015)$. Furthermore, no significant relationship was observed between organizational commitment and its dimensions with the employees' display of political behavior. Although, the employees' organizational commitment is not high in the present study, but it is not influenced by their tendency to display political behavior either. Therefore, it seems that employees' organizational commitment is impressed by other organizational factors such as managers' ethics and temper, observance of organizational justice by supervisors and some other factors which should be studied and assessed by future studies.
\end{abstract}

Keywords: organizational commitment, political behavior, employees, Tehran University of Medical Sciences

\section{Introduction}

Organizations with any type of structure are considered as social systems which form the main foundation of modern societies (Haji Amini et al., 2009). Organizations have two ways communications with people of a community, that is, they make efforts to fulfill the needs of people and community groups, and people also try to direct organizations in order to attain specified and dynamic goals (Hoseinian et al., 2007). Human resources are the heart of an organization and the survival of every organization depends on their human capital (Imani et al., 2012).

The gap between performance and efficiency of organizations make managers choose employees who participate and collaborate with desired commitment for organizational efficiency (Baharlou et al., 2014). In addition, organizations have to compete with each other for employ of engaged, loyal and empower employees to attain 
the goals (Yaghoobi et al., 2010). The concept of organizational commitment is to achieve the dependence between the organization and employees. In fact, strong tendency to work efficiently, maximum effort, and believe in organizational goals and values, are three important elements in the definition of the concept of organizational commitment (Yang \& Chang, 2008). Organizational commitment is a kind of job attitude to identify the employees who enjoy to be a members of the organization and endeavor to present the best their performance (Saatchi et al., 2009; Poorkiani et al., 2010).

Lack of organizational commitment among employees destroys responsibility for attaining the organizational goals, culture and morality, and immorality dominated over the organization. Wu \& Norman showed that there was a positive relationship between job satisfaction and organizational commitment (Hsiao et al., 2012), although Hamidi and Keshtidar suggested that organizational commitment was a new concept which was different from job satisfaction (Hindi, 2014; Hsiao et al., 2012; Hamidi \& Kashti, 1996; Ooi \& Arumugam, 2006). Although, there was not a significant positive relationship in all circumstances between managerial ethics and employees' organizational commitment, rather organizational commitment can be influenced by other factors such as or organizational culture and climate (Dargahi \& Sadat Tehrani, 2014).

On the other hand, political behavior is a kind of organizational behaviors that is unnecessary to be performed formally, but is applied by an individual or group for gaining power in the organization. Political behaviors are narrow-minded, and illegal behaviors which are not allowed by the organization's official authority. They are included negligence, neglecting duty, work aversion, escalating of commitment, protracting works and duties, over conforming, passing the buck, shifting the blame on others, avoiding change, playing dumb, playing safe, buffing, Justifying, scapegoating, being pedantic, and distortion, filtration, misrepresenting, destroying of information and insisting on the past wrong decisions and mistakes (Dargahi, 2013). In other words, political behavior refers to a set of employees' activities influencing work environment in order to achieve personal interest and informal groups' goals in the organization (Ferris et al., 2002; Hadavinejad et al., 2009).

The results of some previous studies indicate that tendency to political behavior in organizations reduces employees' organizational commitment, lay off, work aversion, and avoiding effective communication, have negative impact on their performance (Rahman Seresht, \& Fayazi, 2009; Weber et al., 2009). In addition, the direct impact of employees' perceptions from the political environment can be effective in their degree of commitment aversion (Rahimnia \& Hasanzadeh, 2010). Also, Ferris et al. believe that political climate in the organization can increase work constraint, and reduce job satisfaction and organizational citizenship behavior [OCB] (Ferris et al., 2009).

Since, employees' organizational commitment is related to their performance, values, and beliefs (Dwyer et al., 2003), and individuals who are more committed, are more loyal to organizational goals and values, and play their roles more efficiently (Maurer \& Lippstreu, 2008). Therefore, the present study is aimed to determine the relationship between employees' tendency to organizational behavior and their organizational commitment in Tehran University of Medical Sciences.

\section{Material \& Methods}

This study was a descriptive- analytical, and cross-sectional research induced on the headquarters' employees in the chancellor, Deputy chancellor for education, research, student affairs, Management development and resources planning, International affairs, Health, and Clinical affairs, food and medicine and cultural affair of Tehran University of Medical Sciences in 2013. The entire employees in these sections comprised 700 individuals. The size sample was obtained by Cochran formula in proportion to the number of employees in each of the headquarter areas and determined to be 150 employees. Then, these employees were selected randomly by proper allocation in each area to receive and complete the questionnaires.

The research tools in this study were a researcher-made "political behavior" questionnaire which consisted of 28 questions, and Allen \& Mayer's organizational commitment questionnaire which consisted of 14 questions, including emotional commitment, continuous commitment, and normative commitment (Noor Harun et al., 2006). Also, demographic information of the employees were also collected. In order to rank questionnaires rating, Lickert scale with 5 options very disagrees, relatively agree, agree, and very agree was used with the allocation of the scores from 1 to 5 . The degree of employees' organizational commitment and tendency to display political behavior was determined using descriptive statistical measures of mean, absolute frequency, relative frequency, and valid percentage. Regarding scoring the questions of the organizational commitment questionnaire, rankings of the emotional commitment were 8-18.9, 19-29.9, and 30-40, continuous commitment were $6-13.4,14.5-22.9,23-30$, normative commitment were $6-13.4,14.5-22.9$, and 23-30, and Finally, the 
rankings of organizational commitment were obtained as 20-47, 48-74, and 75-100 which were considered as low, intermediate, and high respectively.

In order to determine the validity of organizational commitment and political behavior, questionnaires, content validity was used. To do so, the main scripts of the questionnaires were translated by two translators from English to Persian. Then, two other translators assessed the translated version regarding the quality of translation, including clarity, application of common language, and finding concept equivalents. The Persian version was translated by a translator into English, and finally the translations were compared with each other. Then questionnaires were given to 12 experts in the fields of health care management and organizational behavior management, and their suggestions were collected. By studying the scientific validity of the questionnaires using CVI or Content Validity Index, this index was 0.83 which indicates the confirmed validity of the questionnaires.

In order to study the reliability of the questionnaires, using test-retest method, the questionnaires were distributed among 20 headquarters employees of Tehran University of Medical Sciences who were not in the research sample, and then the questionnaires were collected. After an interval of two weeks, the questionnaires were completed again by them in order to avoid reminder error. After two-stage data analysis, the correlation coefficient for two types of questionnaires was obtained to be 0.80 . To calculate the integrity and internal consistency of the research tools, Cronbach's alpha for organizational commitment questionnaire was 0.82 , and for emotional commitment, continuous commitment, and normative commitment, was 0.75, 0.80, 0.84, respectively. Finally, for the questionnaire of tendency to political behavior, it was equal to 0.71 . The researcher provided the questionnaires personally to the employees that was in the research sample and collected them again after two weeks. For observing the research ethics, prior to distributing the questionnaires, the required permission was received from the directors and managers of headquarters departments of the university and the goals and objectives of the research were explained to the employees, and in that way, the consent of the respondents to the questionnaires, was gained.

Out of 150 questionnaires, 128 were returned after completion.As a result, the response rate was $85 \%$. The data was collected into Excel and used SPSS 19 software for preparation of descriptive tables and data. For determining the relationship between demographic factors and the variables of organizational commitment and political behavior, $\mathrm{X} 2$ test was applied for determining the relationship between organizational commitment and its dimensions with tendency for political behavior, one-sample T-test, and Pearson statistical technique were used.

\section{Results}

In this research, most of the employees were women (101 individuals, 79\%), 51 (40\%) were between 25 to 35 years old, $49(38 \%)$ were officially or tenure employed, $71(55 \%)$ had bachelor's degree, $40(31 \%)$ had a work experience of 10-20 years, and $69(54 \%)$ were experts in their duties.

Table1. The mean and standard deviation of organizational commitment and its dimensions

\begin{tabular}{ccc}
\hline Variables & Mean & Standard Deviation \\
\hline Continuous Commitment & 17.88 & 0.035 \\
Emotional Commitment & 26.62 & 0.047 \\
Normative Commitment & 17.82 & 0.035 \\
Organizational Commitment & 62.32 & 0.084 \\
\hline
\end{tabular}

Regarding Table 1, the results showed that the degree or level of organizational commitment and each of its dimensions among the employees of Tehran University of Medical Sciences was intermediate.

Table 2. The distribution of absolute and relative frequency of the organizational commitment of headquarters employees at Tehran University of Medical Sciences

\begin{tabular}{ccccc}
\hline Frequency & & $\begin{array}{c}\text { Absolute } \\
\text { (Number) }\end{array}$ & $\begin{array}{c}\text { Relative } \\
\text { (Percentage) }\end{array}$ & $\begin{array}{c}\text { Valid } \\
\text { (percentage) }\end{array}$ \\
\hline Very low & 1 & 1 & 1 \\
Low & 42 & 33 & 33 \\
Intermediate & 72 & 56 & 56 & 9 \\
High & 12 & 9 & 1 \\
Very high & 1 & 1 & 100 \\
Total & 128 & 100 & 100 \\
\hline
\end{tabular}


The results of Table 2 showed that 72(56\%) of employees had intermediate, 43(34\%) of individuals had low and very low organizational commitment. Therefore, more than half of the employees had intermediate, and about one third of them had low and very low organizational commitment.

Table 3. The distribution of absolute and relative frequency of display political behavior tendency in headquarters employees of Tehran University of Medical Sciences

\begin{tabular}{|c|c|c|c|c|}
\hline Frequency & Ranking & $\begin{array}{c}\text { Absolute } \\
\text { (Number) }\end{array}$ & $\begin{array}{c}\text { Relative } \\
\text { (Percentage) }\end{array}$ & $\begin{array}{c}\text { Valid } \\
\text { (percentage) }\end{array}$ \\
\hline Very low & & 2 & 2 & 2 \\
\hline Low & & 110 & 86 & 86 \\
\hline Intermediate & & 6 & 12 & 12 \\
\hline High & & 0 & 0 & 0 \\
\hline Very high & & 0 & 0 & 0 \\
\hline Total & & 128 & 100 & 100 \\
\hline
\end{tabular}

Table 3 indicated that majority (88\%), of headquarters employees of the university had a very low and low tendency to political behavior in the organization.

Table 4. The relationship between employees' demographic information and organizational commitment and tendency to display political behavior in headquarters employees of Tehran University of Medical Sciences

\begin{tabular}{ccccc}
\hline Demographic information & Elements & P & $\mathrm{X}^{2}$ \\
\hline \multirow{2}{*}{ Gender } & Organizational commitment & 0.647 & 4 & 2.48 \\
& Political behavior & 0.184 & 2 & 3.38 \\
Age & Organizational commitment & 0.817 & 12 & 7.58 \\
& Political behavior & 0.179 & 6 & 8.90 \\
Kind of employment & Organizational commitment & 0.273 & 16 & 18.91 \\
& Political behavior & 0.20 & 8 & 10.98 \\
Educational degree & Organizational commitment & 0.128 & 16 & 22.50 \\
& Political behavior & 0.55 & 8 & 16.87 \\
Work experience & Organizational commitment & 0.339 & 16 & 17.74 \\
& Political behavior & 0.157 & 8 & 11.86 \\
Experts in duties & Organizational commitment & 0.015 & 4 & 12.34 \\
& Political behavior & 0.51 & 2 & 1.36 \\
\hline
\end{tabular}

As it can be seen in Table 4, only a significant relationship was found between the employees who were experts in duties with organizational commitment $(\mathrm{P}=0.15)$. In other words, employees who had the organizational levels as experts, had more organizational commitment than those without such tenures. In addition, there was no significant relationship between organizational commitment and tendency to display organizational behavior and other demographic information of employees.

Table 5. The relationship between tendency to display political behavior and organizational commitment dimensions in headquarters employees of Tehran University of Medical Sciences

\begin{tabular}{|c|c|c|c|c|c|c|c|c|c|c|c|c|c|c|c|c|}
\hline \multirow{2}{*}{$\begin{array}{l}\text { Dimensions of } \\
\text { organizational } \\
\text { commitment }\end{array}$} & \multicolumn{4}{|c|}{ Emotional commitment } & \multicolumn{4}{|c|}{ Continuous commitment } & \multicolumn{4}{|c|}{ Normative commitment } & \multicolumn{4}{|c|}{$\begin{array}{c}\text { Organizational } \\
\text { commitment }\end{array}$} \\
\hline & $\mathrm{r}$ & $x^{2}$ & $\mathrm{df}$ & $\mathrm{p}$ & $\mathrm{r}$ & $x^{2}$ & $\mathrm{df}$ & $\mathrm{p}$ & $\mathrm{r}$ & $x^{2}$ & $\mathrm{df}$ & $\mathrm{p}$ & $\mathrm{r}$ & $x^{2}$ & $\mathrm{df}$ & $\mathrm{P}$ \\
\hline $\begin{array}{l}\text { Political } \\
\text { behavior }\end{array}$ & 0.082 & 4.152 & 7.32 & 0.75 & 0.078 & 3.950 & 6.25 & 0.70 & 0.062 & 3.315 & 6 & 0.79 & 0.88 & 4.257 & 8 & 0.83 \\
\hline
\end{tabular}

Regarding Table 5, no significant relationship was found between organizational commitment dimensions and tendency to display political behavior in the headquarters employees of Tehran University of Medical Sciences.

\section{Discussion}

In the present century, with the remarkable growth of displaying political behavior in managing organizations, most of the researchers' efforts in the field of organizational behavior management, are focused on studying employees' perceptions from political behavior. Most of the previous studies in this field, have tried to determine 
the relationship between political behavior and political ethics, organizational commitment, power, organizational efficiency, and employees' satisfaction (Gadot, 2007). The present study for the first time in Iranian healthcare system, addresses the relationship between tendency to display organizational behavior and organizational commitment in headquarters employees of Tehran University of Medical Sciences as the greatest and oldest medical university in Iran, which has the first scientific ranking in Iran and Middle East.

The results of the current study indicated that the employees in Tehran University of Medical Sciences are at an intermediate level of organizational commitment, and all its three dimension. These findings are compatible with the results of other researches (Eskandari, 2010; Koohi Rostam Kalaee, 2012) which were conducted in Iran. However, they are in contradiction with the results of the study in Thailand (Liou \& Cheng, 2010).

Furthermore, "Delgoshaee" and "Kermani" stated that emotional commitment was the dominant commitment in the teaching hospitals in Hamedan city, in Iran (Delgoshaie\&Kermani, 2008). Also, Yaghoobi et al. confirmed, this result in the employees of the hospitals under the supervision of Tehran University of Medical Sciences hospitals (Yaghoobi et al., 2007), although this was compatible with Hen at al. findings among the nurses in Korea (Han et al., 2009). This similarity can be due to identic leadership and management style of human resources and the kind of relationship between employees and managers in the related organizations.

Also, it was revealed that demographic information such as age, gender, kind of employment, educational degree, and work experience had no significant correlation with organizational commitment of the employees, except the employees who were experts in duties $(\mathrm{p}=0.015)$. Porter \& Streets and Nehrir et al stated that the degree of organizational commitment had significant reverse relationship with age and work experience (Steers \& Porter, 1983; Nehrir et al., 2010) which was not similar in contradiction with the results of the present study. Although, Allen \& Mayer reported that there was an indirect relationship between employees' demographic features and organizational commitment (Allen \& Meyer, 1996). Moreover, Peter \& Streets, Allen \& Mayer, and Ensher\& Grant-Vallone declared that employees' job features in an organization, such as kind of employment, job enrichment, and task dependence could have significant positive relationship with organizational commitment (Steers \& Porter, 1983; Nehrir et al., 2010; Allen \& Meyer, 1996; Grant - Vallone \& Ensher, 2001) which was not similar in line with the results of the present study. Although, in a lot of studies, there is a relationship between employees' organizational commitment and their age and work experience (Steers \& Porter, 1983; Nehrir et al., 2010; Allen \& Meyer, 1996; Grant - Vallone \& Ensher, 2001; Allahdadi, 2012), that is not compatible with the results of the present study. This may be related to employees' organizational commitment that is influenced by the rate of organizational justice and fairness which observed by the managers and supervisors. For the same reason, organizational commitment can further be influenced by rightful processes perceived by employees (Yaghoobi et al., 2012; Naami, 2011; Till \& Karren, 2011). "Hasan Poor" could confirm this relationship in the headquarters employees of Tehran University of Medical Sciences in 2012 (Hassanpour, 2014).

On the other hand, display of political behavior in organizations is considered as the source of stress, conflict, poor performance, physical and mental intention to leave the work, burnout, ineffective communication with manager or supervisor, and finally it reduces organizational commitment (Weber et al., 2009). The results of current research indicated that majority of headquarters employees in Tehran University of Medical Sciences had low tendency to display political behavior in their organization. This confirms the results obtained by another similar research at this university in 2012 (Dargahi, 2012). It seems that employees of Tehran University of Medical Sciences believe that improvement of individual and organizational performance depends on non-political environments in their organizations. Although, other researchers reported that effective use of political behavior in organizations promotes organizational performance, affects logical decision-makings, and attaining organizational goals (Fritsch, 2010; Comer, 2010).

Furthermore, the present study revealed that there was no significant relationship between employees' display of political behavior and their demographic information. Although, other researchers reported, this was correlated with age (Ferris \& Kacmar, 1992), gender (Larimer \& Hannagan, 2010; Steel, 2004), work experience (Conner, 2006), and organizational ranking or status (Muhammad, 2007). Also, Dubrin believed that it was not significant related with employees' gender (Dubrin, 1989).

Regarding the main aim of the present research, the relationship between display of political behavior tendency and organizational commitment and its dimensions among headquarters employees of Tehran University of Medical Sciences was not significant $(\mathrm{P}=0.83)$. But, Witt et al. and Cropanzano et al., and the other studies did not confirm this result (Witt et al., 2001; Cropanzano et al., 1997; Vigoda, 2000). Although, Xia \&Elangovan stated that employees' perception from power and politics in the organization as a predictive factor, can 
influence their organizational commitment (Elangovan \& Xie, 2000), which is in contradiction with the result of present study.

The reason for contradiction between the results of current study with other researchers' results due to low tendency to show political behavior among Tehran university of Medical sciences employees and having effect on their organizational commitment is not obvious. But, there is a huge influx of researches on employees' and managers' political behavior in organizations, and its relationship with several variables, such as organizational commitment, job satisfaction, organizational justice, and directors' and managers' ethics which all influence the organizational efficiency and employees' satisfaction (Dargahi, 2013).

\section{Conclusion}

Regarding the development of organizations in new century, concentrating on qualified, proficient, and efficient human resources which is loyal, adaptable, committed and ambitious to organizational goals, is an important factor in organization productivity. On the other hand, organizations' managers are trying hard to provide an environment away from political stresses and behaviors in order to promote organizational commitment.

Although, organizational commitment of employees in Tehran University of Medical Sciences is not high based on the result of this research, loworganizational commitment does not depend on employees' display tendency of organizational behavior. Therefore, the low organizational commitment of employees can be related to other organizational factors such as managers' ethics, observance of organizational justice by supervisors, and some other factors which should be studied in future research and analyzed truly, so that it would be possible to provide necessary solutions and suggestions to increase organizational commitment.

Ethical considerations

Ethical considerations including plagiarism, informed consent, misconduct, data fabrication or falsification, double publication, redundancy, etc. have been completely observed by the authors.

\section{Acknowledgements}

The present study was supported in part by a research grant with code of 16854-31-01-91 from the Deputy for Research and Technology of Tehran University of Medical Sciences. The authors would like to thank Golsa Shaham for her aid in general research program, Zahra varcheh for typing the manuscript, the employees who honestly cooperated with the authors, and honorable managers of this university, and anonymous reviewers for helpful suggestions.

\section{References}

Allahdadi, E. (2002). The relationship of organizational culture with organizational commitment among Mehrabad Airport Custom (MSc. Thesis in management). Shahid Beheshti University, Tehran, Iran.

Allen, N. J., \& Meyer, J. P. (1996). Affective, continuance, and normative commitment to the organization: an examination of construct validity, 49(3), 252-276.

Baharlou, M., Beshlideh, K., Sheykhshabani Hashemi, S. E., \& Naami, A. (2014). Investigation Relationship between leader - member exchange and organizational citizenship behavior: mediating role of psychological empowerment and organizational commitment. Management of Organizational Culture, 12(1), 1-19.

Comer, D. R. (2010). Preparing students to determine personally appropriate political behavior. Retrieved from http://www.jme.sagepub.com

Conner, D. S. (2006). Human resource professionals' perceptions of organizational politics as a function of experience, organizational size, and perceived independence. Journal of Social Psychology, 146(6), 717-732. http://dx.doi.org/10.3200/SOCP.146.6.717-732

Cropanzano, R., Howes, J. C., Grandey, A. A., \& Toth, P. (1997). The relationship of organizational politics and support to work behaviors, attitudes and stress. Journal of Organizational Behavior, 18(2), 159-180. http://dx.doi.org/10.1002/(SICI)1099-1379(199703)18:2<159::AID-JOB795>3.0.CO;2-D

Dargahi, H. (2012). Organizational behavior of employees of Tehran University of Medical Sciences. Journal of Medical Ethics and History of Medicine, 5, 1-7.

Dargahi, H. (2013a). Organizational behavior: ethical or unethical. Iranian Journal of Medical Ethics and History of Medicine, 5(7), 1-14.

Dargahi, H. (2013b). Organizational political behavior management. Iranian journal of Medical Ethics and 
History of Medicine, 5(supplement), 68.

Dargahi, H., \& Sadat Tehrani, G. (2014). The relationship between management ethics and organizational commitment among employees of Tehran University of Medical Sciences. Iranian Journal of Medical Ethics and History of Medicine, 7(1), 43-52.

Delgoshaie, B., \& Kermani, B. (2008). The relationship between organizational climate with organizational commitment among employees and managers of Hamedan University of Medical Sciences. Journal of Gonabad University of Medical Sciences, 4(14), 60-69.

Dubrin, A. J. (1989). Sex differences in endorsement of influence tactics and political behavior tendencies. Journal of Business and Psychology, 4(1), 3-14. http://dx.doi.org/10.1007/BF01023035

Dwyer, S., Richard, O. C., \& Chadwick, K. (2003). Gender diversity in management and firm performance: the influence of growth orientation and organizational culture. Journal of Business Research, 56(12), 1009-1019. http://dx.doi.org/10.1016/S0148-2963(01)00329-0

Elangovan, A. R., \& Xie, J. L. (2000). Effects of perceived power of supervisor on subordinate work attitudes. Leadership \& Organization Development journal, 21(6), 319-328. http://dx.doi.org/10.1108/01437730010 343095

Eskandari, F. (2010). Study of relationship between nurses' structural and psychological empowerment with their organizational commitment in Zanjan's hospitals. Thesis in nursing MSc. School of Nursing \& Midwifery, Shahid Beheshti University of Medical Sciences, Tehran, Iran.

Ferris, G. R., \& Kacmar, K. M. (1992). Perceptions of organizational politics. Journal of Management, 18(4), 93-116. http://dx.doi.org/10.1177/014920639201800107

Ferris, G. R., Adams, G., Kolodinsky, R. W., Hochwarter, W. A., \& Ammeter, A. P. (2002). Perceptions of organizational, politics: theory and research directions. Journal of Managerial Issues, 1(1), 179-254. http://dx.doi.org/10.1016/s1475-9144(02)01034-2

Ferris, G. R., Rogers, L. M., Blass, F. R., \& Hochwarter, W. A. (2009). Interaction of job limiting pain and political skill on job satisfaction and organizational citizenship behavior. Journal of Managerial Psychology, 24, 504-608. http://dx.doi.org/10.1108/02683940910989002

Fritsch, J. (2010). Toward theory of personal politics. Human Resource Development Review, 9(3), $236-248$.

Gadot, E. V. (2007). Citizens' perceptions of politics and ethics in public administration: a five year national study of their relationship to satisfaction with services, trust in governance and voice orientations. Journal of Public Adminstration Research Theory, 17(2), 285-305. http://dx.doi.org/10.1093/jopart/muj018

Grant-Vallone, E. J., \& Ensher, E. A. (2001). An examination of work and personal life conflict, organizational support, and employee health among international expatriates. International Journal of Intercultural Relations, 25, 261-278. http://dx.doi.org/10.1016/S0147-1767(01)00003-7

Hadavinejad, M., Alizade Sani, M., \& Khaefi Elahi, A. A. (2009). Manager's political professions, employee's organizational politics perceptions and resistance to change. Iranian Journal of Management Sciences, 16(4), 119-137.

Haji Amini, Z., Vafadar, Z., Rahmani, R., Khaghanizade, M., \& Daneshmandi, M. (2009). Effect of implementation of suggestion's system on the extend of organizational commitment of the personnel working in ICU. Iranian Journal of Critical Care Nursing, 2(1), 21-26.

Hamidi, M., \& Kashti Dar, M. (1996). The review of organizational commitment in colleges of physical education in Iran. Harekat, 54, 43-54.

Han, S. S., Moon, S. J., \& Yun, E. K. (2009). Empowerment, Job satisfaction, and organizational commitment: comparison of permanent and temporary nurses in Korea. Applied Nursing Research, 87, 874-887. http://dx.doi.org/10.1016/j.apnr.2009.06.004

Hassanpour, F. (2014). The study of relationship between organizational Justice with organizational commitment among headquarters employees of Tehran University of Medical Sciences (MSc. Thesis in Health Care Management). School of Allied Medicine, Tehran University of Medical Sciences, Tehran, Iran.

Hindi, J. (2014). The Hungry Ghosts. Translated by Rezaei Nejad A. R. Tehran: Fara.

Hoseineian, S., Majidi, A., \& Habibi, A. (2007). Effective factors on organizational commitment to increase human resource effectiveness. Faslname-ye Danesh-e-Entezami, (2), 9-25. 
Hsiao, H. C., Chang, J. C., \& Tu, Y. L. (2012). The influence of hospital organizational culture on organizational commitment among nursing executives. African Journal of Business Management, 6(44), 10889-10895,

Imani, R., Asefzadeh, S., \& Mamikhani, J. (2012). Comparative study on health human resources composition in the Eastern Mediterranean Countries (2007-2008). The Journal of Qazvin University of Medical Sciences, $1514,5-12$.

Kouhi, R. Z. (2012). Study of organizational commitment and its dimensions in Tehran University of Medical Sciences hospitals. Thesis in Nursing MSc. School of Nursing \& Midwifery, Tehran University of Medical Sciences, Tehran, Iran.

Larimer, C. W., \& Hannagan, R. J. (2010). Gender differences in follower behavior.an experimental study of reaction to ambitious makers. Political Life Sciences, 29(2), 40-54.http://dx.doi.org/10.2990/29_2_40

Liou, S. R., \& Cheng, C. Y. (2010). Organizational climate, organizational commitment and intention to leave amongst hospital nurses in Taiwan. Journal of Clinical Nursing, 139(11-12), 1635-1644. http://dx.doi.org/10.1111/j.1365-2702.2009.03080.x

Maurer, T. J., \& Lippstreu, M. (2008). Who will be committed to an organization that provides support for employee development? Journal of Management Development, 27(3), 328-347. http://dx.doi.org/10.1108/ 02621710810858632

Muhammad, A. H. (2007). Antecedents of organizational politics perceptions in Kuwait business organizations. An International Business Journal, 17(4), 234-247. http://dx.doi.org/10.1108/10595420710844325

Naami, A. (2011). A study between organizational justice and organizational citizenship behavior in industrial organization in Ahvaz. Psychology Journal, 3, 79-92.

Nehrir, B., Ebadi, A., Tofighi, S. h., KarimiZarchi, A. A., \& Honarvar, H. (2010). Relationship of job satisfaction and organizational commitment in hospital nurses. Journal of Militry Medicine, 2(1), 23-26.

Noor Harun, A. K., \& Noor HasralNizan, M. N. (2006). Evaluating the psychometric properties of Allen and Meyer's organizational commitment scale: a cross - cultural application among Malaysian academic librarians. Malaysian Journal of Library \& Information Science, 11(1), 89-101.

Ooi, K. B., \& Arumugam, V. (2006). The influence of corporate culture on organizational commitment: case study of semiconductor organizations in Malaysia. Sunway Academic Journal, 3, 99-115.

Poorkinani, M., \& ZamaniFard, M. H. (2010). Organizational commitment in light of organizational Justice. Misaqe Modiran, 68, 63-68.

Rahimnia, F., \& Hasanzadeh, J. F. (2010). The moderating role of organizational justice on perception of organization politics and communication apprehension. Change Management Bulletin, 1(2), 22-39.

Rahman Seresht, J., \& Fayazi, M. (2000). The relationship between conception of employees from power and organizational politics with their commitment and performance. Human and Social Sciences Bulletin, 8(29), 73-96.

Saatchi, M., Ghasemi, N., \& Namazi, S. (2009). An investigation into the relationship between principals' Job motivation and Job satisfaction and organizational commitment of Marvdasht high school teachers. Quarterly Journal of New Approaches in Educational Administration, 1(2), 153-175.

Steel, G. (2004). Gender and political behavior in Japan. The Social Science Journal, 7(2), 223-244.

Steers, R. M., \& Porter, L. W. (1983). Motivation and work behavior (4th ed., pp. 12-44). London: McGrowhill.

Till, R. E., \& Karren, R. (2011). Organizational Justice perceptions and pay level satisfaction. Journal of Managerial Psycholog, 26(1), 35-45. http://dx.doi.org/10.1108/02683941111099619

Vigoda, E. (2000). Organizational politics, job attitudes, and work outcomes: exploration and implications for the public sector. Journal of Vocational Behavior, 57(3), 326-347.http://dx.doi.org/10.1006/jvbe.1999.1742

Weber, M. R., Doun Finley, D. A., Crawford, A., \& Rivera, D. (2009). An explanatory study identifying soft skill competencies in entry - level managers. Tourism Hospital Research, 9(4), 353-361. http://dx.doi.org/10.1057/thr.2009.22

Witt, L. A., Hilton, T. F., \& Hochwarter, W. A. (2001). Addressing politics in matrix team. Group \& Organization Management, 26(2), 230-247. http://dx.doi.org/10.1177/1059601101262006

Yaghoobi, M., Esfahani, S., \& Gorgi, H. (2007). The relationship between organizational justice with job 
satisfaction and organizational commitment amongst Isfahan University of Medical Sciences hospitals' employees. Journal of Health Management, 12(25), 25-32.

Yaghoubi, M., Afshar, M., \& Javadi, M. (2012). A study of relationship between the organizational justice and organizational citizenship behavior among nurses in selected hospitals of Isfahan University of Medical Sciences. Iranian Journal of Nursing and Midwifary Research, 17(6), 456-460.

Yaghoubi, M., Karimi, S., Raeisi, A. R., Javadi, M., \& Sharbafchi, N. (2010). A study of relationship between the learning organization and organizational commitment among managers in educational hospitals of Isfahan University of Medical Sciences. Health Information Management, 7(2).

Yang, F. H., \& Chang, C. C. (2008). Emotional labor, Job satisfaction and organizational commitment amongst clinical nurses: a questionnaire survey. International Journal of Nursing Studies, 45(6), 879-887. http://dx.doi.org//0.1016/j.ijnurstu.2007.02.001

\section{Copyrights}

Copyright for this article is retained by the author(s), with first publication rights granted to the journal.

This is an open-access article distributed under the terms and conditions of the Creative Commons Attribution license (http://creativecommons.org/licenses/by/3.0/). 